\title{
Поверхностное дефектообразование в CdTe при воздействии излучения $\mathrm{CO}_{2}$-лазера
}

\author{
(C) П.С. Шкумбатюк \\ Дрогобычский педагогический университет им. И. Франко, \\ 82100 Дрогобыч, Украина \\ E-mail: tarasik82@gmail.com
}

(Получена 30 августа 2017 г. Принята к печати 10 октября 2017 г.)

Исследовано действие непрерывного излучения $\mathrm{CO}_{2}$-лазера на сколотую поверхность (110) CdTe. На основании анализа морфологии облучаемой и облученной поверхности показано, что образование наблюдаемых дефектов обусловлено испарением CdTe в области дислокаций.

DOI: 10.21883/FTP.2018.09.46144.8718

\section{1. Введение}

При исследовании влияния действия импульсного лазерного излучения на $\mathrm{CdTe}[1,2]$ в области облучения обнаружено неоднородное испарение $\mathrm{Cd}$ и Те, в работах [3-5] - рекристаллизация и образование поверхностных структур. При облучении CdTe в [6] показано, что на изменение электрофизических свойств облученного CdTe влияет увеличение концентрации дислокаций.

Поиски методов исследования и управляемого изменения дефектного состояния $\mathrm{CdTe}$ дают возможность более качественно понять влияние дефектов и их распределение на свойства CdTe. C этой целью в данной работе использовано действие непрерывного излучения $\mathrm{CO}_{2}$-лазера. При этом предполагается, что независимо от механизма поглощения существенного различия в тепловом механизме действия импульсного и непрерывного лазерного излучения нет, за исключением управления временно́й зависимостью температуры нагревания.

\section{2. Методика эксперимента}

Для исследования изменения дефектного состояния $\mathrm{CdTe}$ действием непрерывного излучения $\mathrm{CO}_{2}$-лазера использовали $\mathrm{CdTe}$, выращенный с жидкой и газовой фазы. Сколотые образцы с ориентацией (110), площадью поверхности $0.04-0.25 \mathrm{~cm}^{2}$, толщиной $0.03-0.1 \mathrm{~cm}$ и удельным сопротивлением $10^{3}-10^{5}$ Ом - см облучали на воздухе при комнатной температуре излучением $\mathrm{CO}_{2}$-лазера ЛГН-703. Оксидную пленку удаляли в $\mathrm{HCl}$. Морфологию поверхности исследовали оптическим микроскопом. Для управления плотностью мощности излучения использовали сферическое алюминированное зеркало с фокусным расстоянием $15 \mathrm{~cm}$. Плотность мощности излучения определяли по разности диаметров исходного и сфокусированного лучей. По изменению морфологии облучаемой поверхности CdTe определяли начальные параметры облучения. Среднее вре- мя облучения составляло $2-10$ с, плотность мощности $(3-6) \cdot 10^{2} \mathrm{BT} / \mathrm{cm}^{2}$.

Электрофизические свойства облученного $\mathrm{CdTe}$ в области дефектов исследовали методом поверхностной фотоэдс в вакууме в области температур 90-300 К при импульсном освещении длиной волны от 0.6 мкм с промежутком 0.05 мкм. Измерения поверхностной фотоэдс проводились при отсутствии внешнего источника напряжения. Полярность определяли по измерению фотоэдс поверхностной барьерной $n-p$-структуры $\mathrm{Si}-\mathrm{B}$. При положении пластины (полевого электрода) в $n$-области фотоэдс положительной полярности, в p-области отрицательной.

\section{3. Результаты эксперимента и обсуждение}

Не учитывая зависимости дефектообразования от параметров облучения, обнаружена общая закономерность изменений дефектного состояния облученной поверхности исследуемого CdTe. При начальных параметрах облучения поверхность (рис. $1, a)$ имеет пятна размером 1-3 мкм с неравномерным распределением, в области действия облучения их количество $10^{4}-10^{5} \mathrm{~cm}^{-2}$. На противоположной поверхности независимо от толщины и типа исследуемого CdTe их не обнаружено. Время облучения влияет на структуру и размер дефектов на облучаемой поверхности, и генерирует их на противоположной необлучаемой поверхности. На облучаемой поверхности (рис. $1, b)$ наблюдали морфологию дефекта у формы конуса или усеченного конуса диаметром 20-30 мкм. Боковая поверхность в виде ступенек с началом в вершине конуса. Дефекты имеют углубление по периметру основания относительно плоскости облучаемой поверхности.

При увеличении времени облучения (рис. 1,c) на облучаемой поверхности обнаружено уменьшение наблюдаемой концентрации дефектов на 1-2 порядка. На уменьшение концентрации указывает увеличение размеров дефектов до 100-300 мкм и перекрытие их центров образования. Изменение размеров обусловлено 


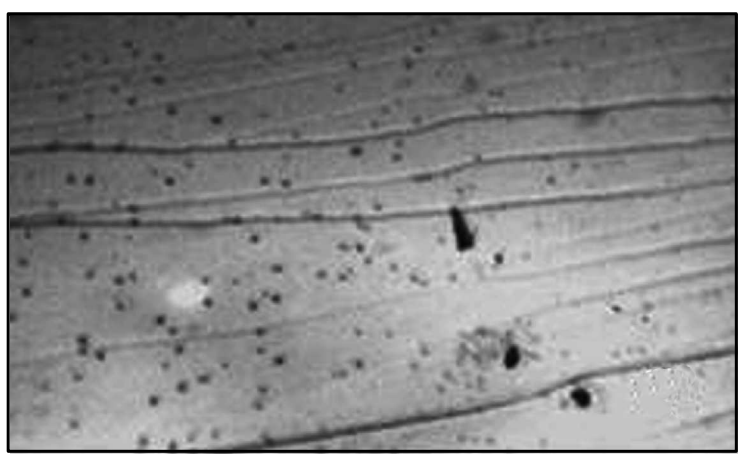

$a$

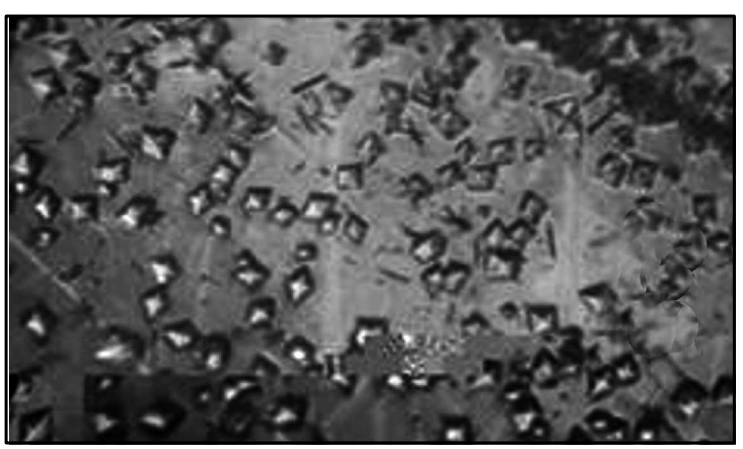

$b$

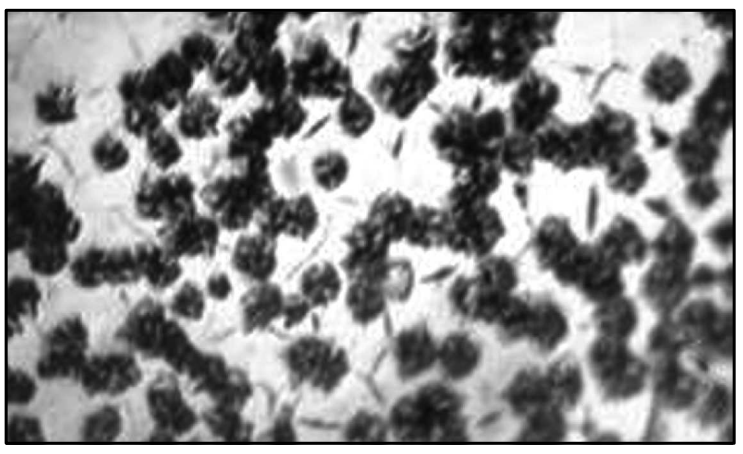

$c$

Рис. 1. Морфология поверхности СdTе: $a-$ облученная область $\mathrm{CO}_{2}$-лазером, время облучения $t_{1} ; b-$ облученная область $\mathrm{CO}_{2}$-лазером, время облучения $t_{2}>t_{1}, c-t_{3}>t_{2}$.

увеличением поглощения излучения в области дефектов и пороговым значением параметров облучения, за которым происходит интенсивное испарение компонентов CdTe с облучаемой поверхности. В области вершины конуса наблюдаемых дефектов обнаружено скопление $\mathrm{CdO}$. Наличие и площадь поверхности $\mathrm{CdO}$ зависят от времени облучения и исходного СdTe. Отметим, что при равных параметрах облучения наличие и площадь поверхности $\mathrm{CdO}$ больше для $\mathrm{CdTe}$, выращенного из жидкой фазы. Наблюдаемое накопление $\mathrm{CdO}$ на поверхности дефектов обусловлено двумя механизмами: нестехиометрией и увеличением концентрации дислокаций в области дефектов. На рис. 2,a показана поверхность дефектов после удаления оксидной пленки в $\mathrm{HCl}$. Поверхность в начальной области дефекта имеет вид неупорядоченно размещенных ячеек и Те нитевидной формы. После селективного травления в дефектных областях обнаружена плот- ная упаковка неупорядоченно размещенных дислокаций (рис. 2, $b$ ).

При увеличении параметров облучения происходит плавление $\mathrm{CdTe}$ в области дефектов (рис. 2,c). Наблюдаемые дефекты имеют форму конуса диаметром $300-500$ мкм, с боковой поверхностью в виде кольцевых ступенек, параллельных до основания, с началом в вершине конуса. Площади ступенек уменьшаются от основания до вершины конуса. Отметим, что такой вид дефектов с пересекающими ступеньками и диаметром $30-50$ мкм наблюдали на облученной поверхности CdTe выращенного из газовой фазы с параметрами облучения, не приводящими к плавлению в области дефектов.

Механизм образования поверхностного вида наблюдаемых дефектов искали методом сравнения вида облученной сколотой поверхности и облученной поверхности с

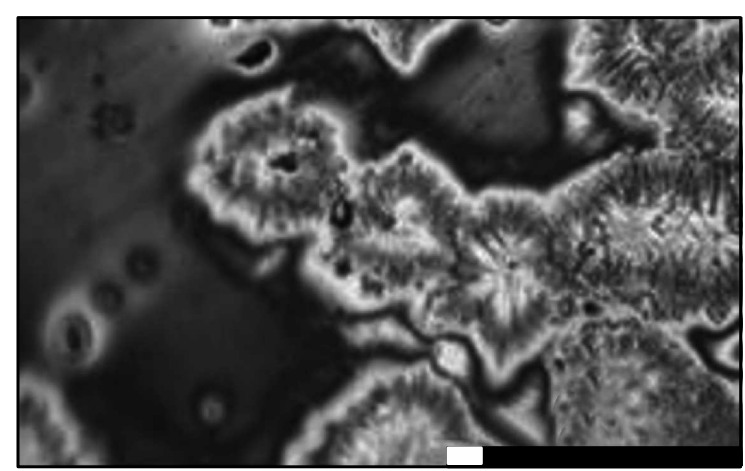

$a$

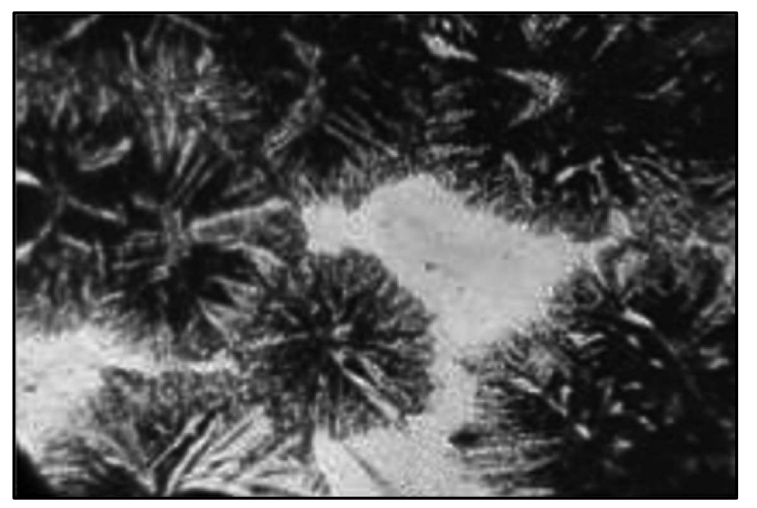

$b$

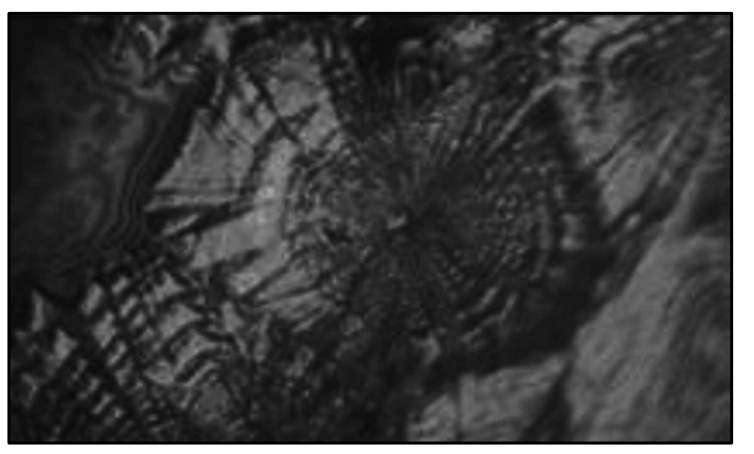

Рис. 2. Вид области поверхности $\mathrm{CdTe}$, облученной $\mathrm{CO}_{2}$-лазером: $a$ - после травления в $\mathrm{HCl}, b-$ после селективного травления в области дефекта, $c-$ параметры облучения соответствуют плавлению исследуемого СdTe. 
предварительно измененной морфологией областей поверхности окислением, механическим повреждением и травлением. Выявленный в виде тип дефектов (рис. 1, $a$ ) не образуется под оксидной пленкой на предварительно окисленных частях облучаемой поверхности. При предварительном нанесении на облучаемую поверхность дефектов в виде неглубоких царапин или невидимых в оптическом микроскопе повреждений в этих областях наблюдали увеличение концентрации выявленных дефектов.

Отсутствие наблюдаемых дефектов под оксидной пленкой и увеличение концентрации дефектов в области механических повреждений указывает на механизм их образования, обусловленный испарением компонентов $\mathrm{CdTe}$ в местах дислокаций. Концентрация дислокаций в местах наибольшего скопления облучаемого $\mathrm{CdTe}$ составляла $(5-8) \cdot 10^{4} \mathrm{~cm}^{-2}$ (рис. $\left.3, a\right)$.
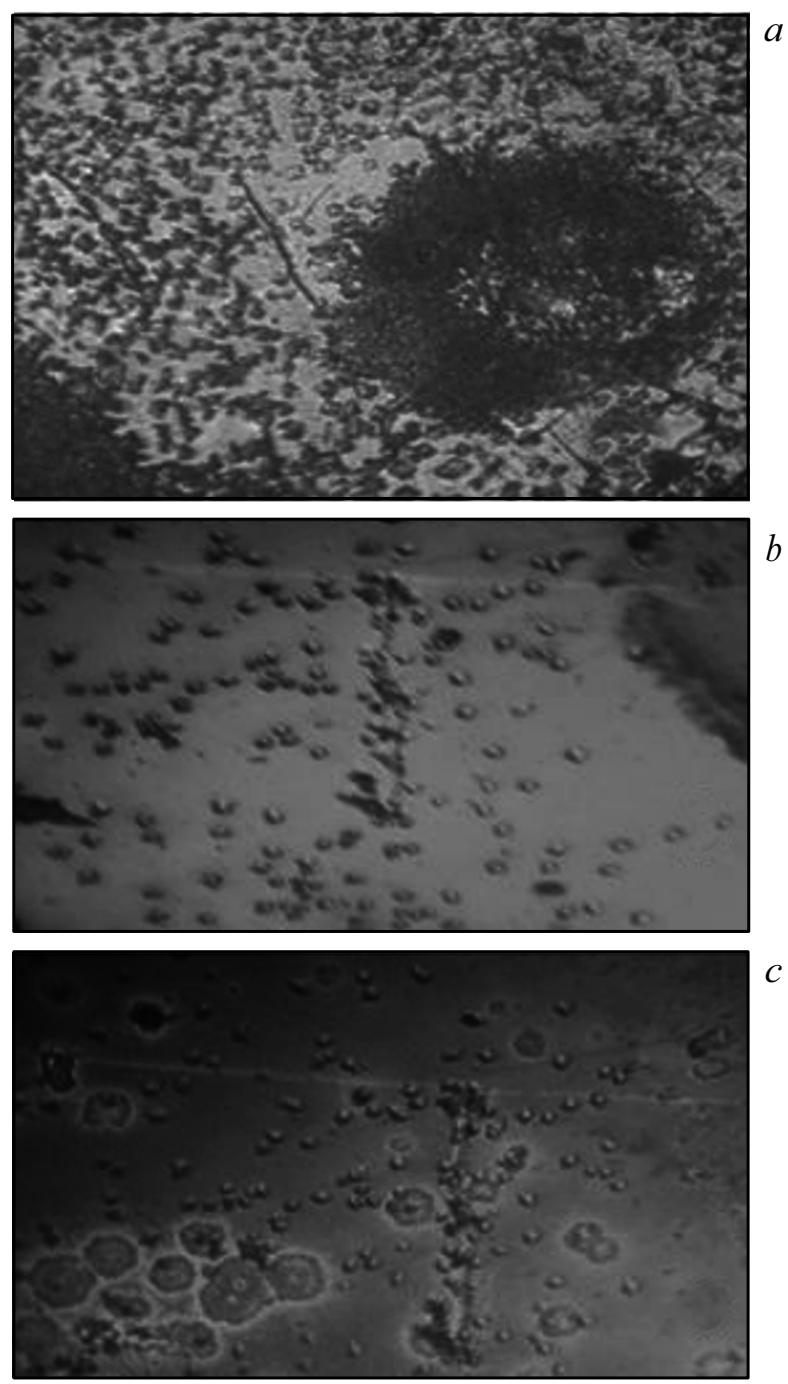

Рис. 3. $a-$ селективное травление исходного $\mathrm{CdTe}, b-$ селективное травление механически поврежденного $\mathrm{CdTe}$ до облучения, $c$ - после облучения $\mathrm{CO}_{2}$-лазером, время облучения $t_{1}$ (повреждение указано стрелкой).
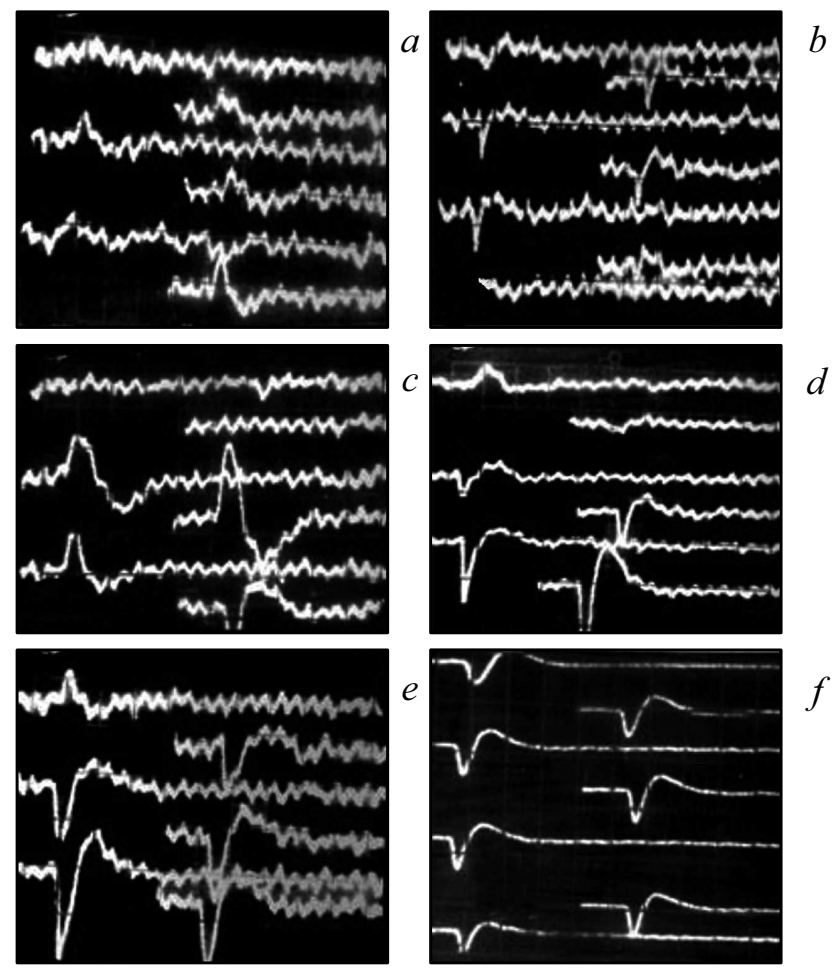

Рис. 4. Осциллограммы поверхностной фотоэдс от $\lambda=0.6$ мкм с промежутком 0.05 мкм (сверху-вниз): $a-$ исходный, $b-$ облученный, время облучения $t_{1}, c-$ время облучения $t_{2}, d-$ после травления в $\mathrm{HCl}, e-$ время облучения $t_{3}, f-T=300 \mathrm{~K}$. Температура измерения для всех остальных кривых (сверху-вниз): 90, 125, 160, 200, 250, $300 \mathrm{~K}$.

Для поиска подтверждения дислокационной природы обнаруженных дефектов на облучаемой поверхности $\mathrm{CdTe}$ использовали метод сравнения вида необлученной сколотой поверхности, предварительно протравленной в селективном травителе и после облучения. На рис. $3, b$ показана протравленная поверхность с меткой в центре в виде царапины с увеличенной концентрацией дислокаций. После действия излучения с начальным значением параметров облучения (рис. 3,c) только в некоторых областях на дислокациях обнаружены плоские дефекты диаметром 10-40 мкм. Это удовлетворительно подтверждает дислокационную природу обнаруженных дефектов облучаемой поверхности СdTe.

Величина сигнала и полярность поверхностной фотоэдс облученного CdTe (рис. 4) зависит от электрофизических свойств облученной поверхности и температуры.

Наблюдаемое различие полярности фотоэдс сколотого (рис. 4, $a$ ) и облученного вида (рис. 1,a) поверхности (рис. $4, b$ ) указывает на увеличение концентрации акцепторов облученной поверхности. При исследовании облученной поверхности (рис. 2, $a, b$ ) наблюдали увеличение сигнала фотоэдс (рис. $4, c, d)$. Следует отметить, что действием излучения $\mathrm{CO}_{2}$-лазера выявлена возможность формировать на поверхности CdTe барьерные структуры 
размером $100-500$ мкм с поверхностью $p$-типа проводимости (рис. $4, e, f)$.

На облученной поверхности наблюдали зависимость величины сигнала и полярности поверхностной фотоэдс от температуры. Отсутствие или уменьшение сигнала фотоэдс в области $T=90-160 \mathrm{~K}$ и изменение полярности указывают на зависимость электрических свойств дефектной области от объемной концентрации носителей заряда. С увеличением размеров дефектов зависимость уменьшается.

\section{4. Заключение}

В работе показана возможность обнаружения дислокаций на сколотой поверхности (110) CdTe методом теплового действия излучения $\mathrm{CO}_{2}$-лазера. При увеличении времени облучения в области дефекта обнаружено скопление $\mathrm{CdO}$. На основании наблюдаемой морфологии дефектов сделано предположение о несоответствии стехиометрии в области дислокации.

\section{Список литературы}

[1] В.Н. Бабенцов, А. Байдулаева, А.И. Власенко, С.И. Горбань, Б.К. Даулетмуратов, П.Н. Мозоль. ФТП, 27 (10), 1618 (1993).

[2] Л.А. Головань, П.К. Кашкаров, В.М. Лакеенков, Ю.Н. Сосновских, В.Ю. Тимошенко, Н.Г. Чеченин. ФТТ, 40 (2), 209 (1998).

[3] В.Н. Бабенцов, Н.И. Табаев. ФТП, 32 (1), 32 (1998).

[4] И.Л. Шульпина, Н.К. Зеленина, О.А. Матвеев. ФТТ, 42 (3), 548 ( 2000).

[5] А. Байдулаева, М.Б. Булах, А.И. Власенко, А.В. Ломовцев, П.Е. Мозоль. ФТП, 38 (1), 26 (2003).

[6] А. Байдулаева, Б.М. Булах, Б.К. Даулетмуратов, Б.Р. Джумаев, Н.Е. Корсунская, П.Е. Мозоль, Г. Гарягдыев. ФТП, 26 (5), 801 (1992).

Редактор Г.А. Оганесян

\section{Superficial formation of defects in CdTe at influence of radiation $\mathrm{CO}_{2}$-laser}

\section{P.S. Shkumbatjuk}

State Pedagogical University of I. Franko, 82100 Drogobych, Ukraine

Abstract Action of continuous radiation $\mathrm{CO}_{2}$-laser on the chopped off surface (110) CdTe is investigated. On the basis of the analysis of morphology of the irradiated and irradiated surface it is shown that formation of observable defects is caused, evaporation CdTe in the field of dispositions. 